\title{
(Un)predictability in rip channel systems
}

\author{
Daniel Calvete, ${ }^{1}$ Giovanni Coco, ${ }^{2}$ Albert Falqués, ${ }^{1}$ and Nicholas Dodd ${ }^{3}$ \\ Received 18 September 2006; revised 16 January 2007; accepted 30 January 2007; published 8 March 2007.
}

[1] Predicting the development of rip channel systems on beaches is relevant for beach safety, nearshore mixing and dispersion, and has been puzzling researchers for decades. Field observations and computer simulations have focused on predicting the spacing and growth time of rip channels as a function of wave characteristics. A satisfactory predictor of rip channel spacing and growth time has not yet been proposed. Here, we show that the lack of predictability of rip channels is an inherent property of the system related to the high sensitivity to the bathymetry prior to pattern development. Sensitivity to the initial cross-shore profile appears to be as important as sensitivity to wave height. Although we might be able to predict rip channel characteristics, the information required by such predictors will need to account for the underlying bathymetry. Implications arising from this study are that other geomorphic patterns could display similar sensitivity. Citation: Calvete, D., G. Coco, A. Falqués and N. Dodd (2007), (Un)predictability in rip channel systems, Geophys. Res. Lett., 34, L05605, doi:10.1029/2006GL028162.

\section{Introduction}

[2] Rip currents are common features of nearshore circulation that develop in the surfzone and that typically extend from the shoreline to offshore of the wave breaking area. Rip currents are usually identified as narrow, offshore-directed, jet-like flows characterized by strong speed even though their appearance implies the development of surfzone circulation cells. They are relevant because they pose a hazard to swimmers [Short and Hogan, 1995], and they provide a mechanism for the mixing of pollutants [Bohem, 2003] and exchange of nutrients [Talbot and Bate, 1993]. Commonly, rip currents are linked to seabed depressions called rip channels. Researchers have focused on the initial formation and subsequent evolution of rip channels through laboratory, field and numerical studies [see Van Enckevort et al. 2004 and MacMahan et al. 2006 for observational and modeling reviews]. In some cases rip channels are driven by largerscale bathymetric features (e.g., offshore submarine canyons) that control the appearance and location of individual rips [Long and Özkan-Haller, 2005]. On barred beaches, rip channels emerge as a quasi-regularly spaced pattern and the overall sandbar crest appears as a sequence of crescentic shapes. Consequently, the characteristic that has attracted most of the attention is the prediction of the alongshore spacing of rip channels.

\footnotetext{
${ }^{1}$ Dept. de Física Aplicada, Universitat Politécnica de Catalunya, Barcelona, Spain.

${ }^{2}$ National Institute of Water and Atmospheric Research, Hamilton, New Zealand. UK.

${ }^{3}$ School of Civil Engineering, University of Nottingham, Nottingham,

Copyright 2007 by the American Geophysical Union. 0094-8276/07/2006GL028162\$05.00
}

[3] Under the general assumption that larger inputs of energy in the nearshore result in the development of bedforms characterized by larger spacing, most of the field observations [e.g., Huntley and Short 1992] have unsuccessfully attempted to relate rip current spacing to wave characteristics (height and period) or to parameters related to the distance between the shoreline and the alongshore sandbar crest. Failure to relate this latter or similar parameters to rip channel spacing and growth time was ascribed to the difficulty in the estimation of the bar crest location. More recent studies have obtained reliable estimates of the bar crest position from video images [Van Enckevort et al., 2004; Holman et al., 2006], but have still failed to explain variations in rip channel spacing. Also, under similar hydrodynamic conditions, rip channels may or may not appear (this observation applies to the majority of morphodynamic patterns but has still not found any explanation).

[4] Numerical models developed using linear stability analysis or the solution of the nonlinear shallow water equations have been used, under a number of simplifying assumptions ranging from monochromatic and normally incident waves to linear seabed slope. These models have established the role of self-organization in the development of rip channels [see Calvete et al. 2005, for a review] but have not been able to unequivocally predict rip channel spacing. Overall, numerical models predict an increase of rip channel spacing with either wave height (for unbarred beach) or the distance between the shoreline and the sandbar crest. Nevertheless, scatter is present also in numerical simulations [up to a factor of 4 according to results presented in Damgaard et al., 2002]. Recently, with respect to the regularity of the emerging pattern, the variation in the mean rip channel spacing has been related to the directional spreading of short waves [Reniers et al., 2004].

[5] We here analyze why field observations and numerical studies do not show any conclusive predictive relationship between the growth time and spacing of rip channels and predictors such as wave height or the distance between the shoreline and the sandbar crest. Our results indicate the potential for every aspect of the cross-shore profile geometry of barred-beaches to cause substantial variability in rip channel growth and alongshore spacing. Although an open challenge (and not the objective of this work), our results also point at inherent difficulties in the possibility of developing such a predictor for nearshore systems. Our results also show that certain profile shapes might require a long time to respond to hydrodynamic forcing conditions so that the (expected) pattern might not develop at all.

\section{Methods}

[6] The numerical model used herein [Calvete et al., 2005] is based on linear stability analysis. The model considers depth- and time-averaged momentum and conti- 


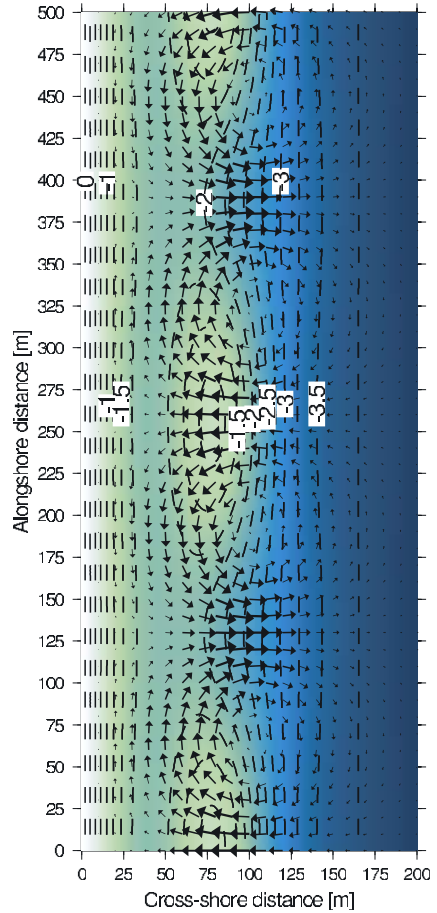

Figure 1. Rip channel configuration. Size and direction of arrows indicates the associated flow pattern.

nuity equations coupled with wave-energy, phase, and sediment-conservation equations. Waves, described through a Rayleigh distribution and driving flow circulation through radiation stresses, are assumed to dissipate their energy according to the [Church and Thornton, 1993] model while bed shear and Reynolds stresses are described using commonly adopted parameterizations [see Calvete et al., 2005, for parameterization details and boundary conditions]. Fluxes of sediment are evaluated using a widely adopted formulation [Soulsby, 1997] and include the contribution of bedload and suspended load, as well as a term that accounts for gravitational downslope transport.

[7] A simple solution of the system's equations, usually defined as the basic state, consists of an alongshore uniform equilibrium (or slowly evolving) state. The basic state is perturbed and equations are subsequently linearized as in any standard linear stability analysis [Falqués et al., 2000]. Perturbations are imposed on the sea-surface, seabed, velocity field, energy, and phase. For a given set of forcing conditions (wave height, period) and a defined cross-shore profile, outputs of the analysis are the characteristics of the fastest-growing instability of the system: the characteristic growth time $\tau$ (the e-folding time) and the alongshore periodicity of the pattern $\lambda$. The characteristics of the fastest-growing pattern refer to the initial formation stages and do not account for nonlinear phenomena like merging and splitting of the channels that might subsequently occur. Although strictly valid only in the linear regime, emerging spatial patterns of flow circulation and morphology closely resemble those observed in nature (Figure 1 shows a typical output, morphology and related flow pattern, of the linear stability analysis). Also, recent work on surfzone morphodynamics indicates that differences between predictions using linear stability analysis and nonlinear numerical simulations can be negligible [Garnier et al., 2006].

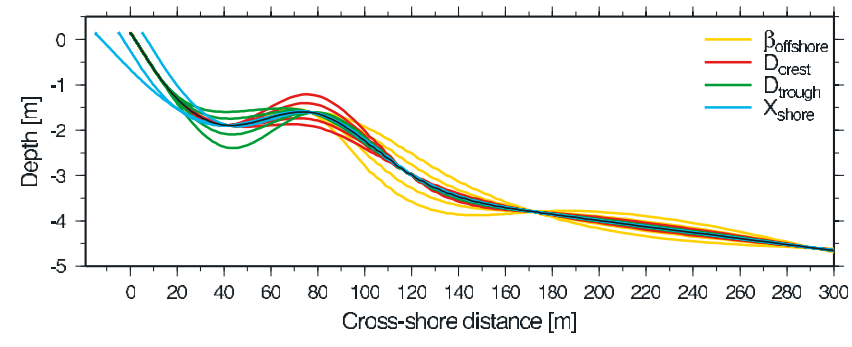

Figure 2. Geometry of initial cross-shore profiles used in the numerical simulations.

[8] Key to the present study is the shape of the singlebarred cross-shore profile initially considered to be uniform in the alongshore direction. We have described this profile by defining water depths at specific cross-shore positions. All the initial configurations considered herein are realistic. The effect of changing the profile shape and the resulting changes in the rip channel spacing, $\lambda$ and e-folding time $\tau$ will be discussed in the following section.

\section{Results}

[9] For the simulations presented herein, the offshore wave height, $H_{r m s}$, has been kept equal to $1.5 \mathrm{~m}$, waves have been assumed to approach the shore normally and with an incident wave period of $12 \mathrm{~s}$. The resulting rip channel configuration and the related flow pattern is shown in Figure 1. We have run simulations for shapes of the bottom profile primarily differing in the slope offshore of the sandbar, $\beta_{\text {offshore }}$, the depth over the sandbar crest, $D_{\text {crest }}$, and trough, $D_{\text {trough }}$, and the crest position, $X_{\text {shore }}$ (Figure 2). Changes in the shape of the cross-shore profile affect wave transformation and breaking locations. We characterize wave transformation using $X_{B}$, the distance between the shoreline and the position of maximum dissipation due to

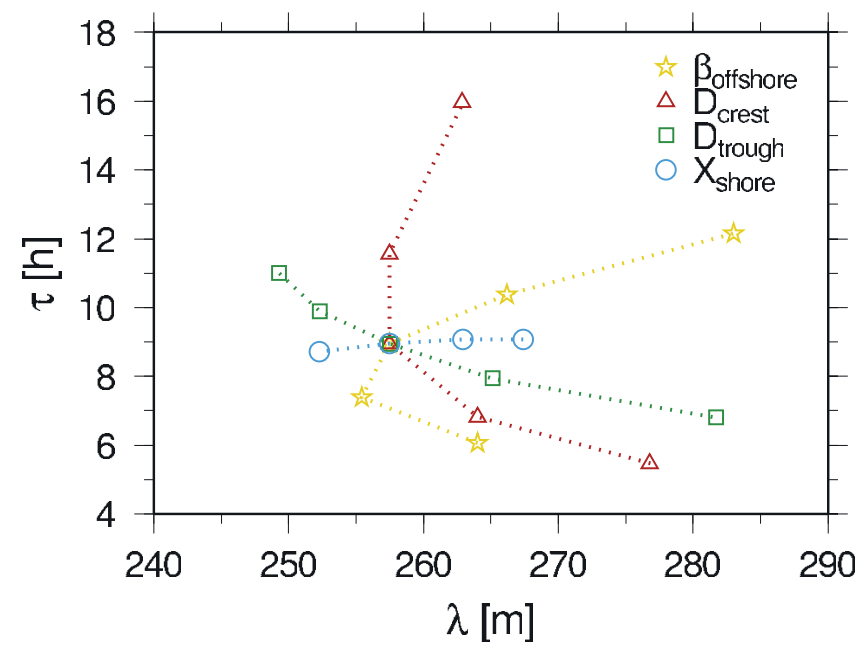

Figure 3. Growth time $(\tau)$ as a function of rip channel spacing $(\lambda)$. Different aspects of the cross-shore profile have a different effect on $\tau$ and $\lambda$ relationship: while $X_{\text {shore }}$ and $D_{\text {trough }}$ linearly affect this relation, the sensitivity of rip channel to $D_{\text {crest }}$ and $B_{\text {offshore }}$ is more complicated so that large rip channel spacing can be associated to the smallest or the largest growth rates. 

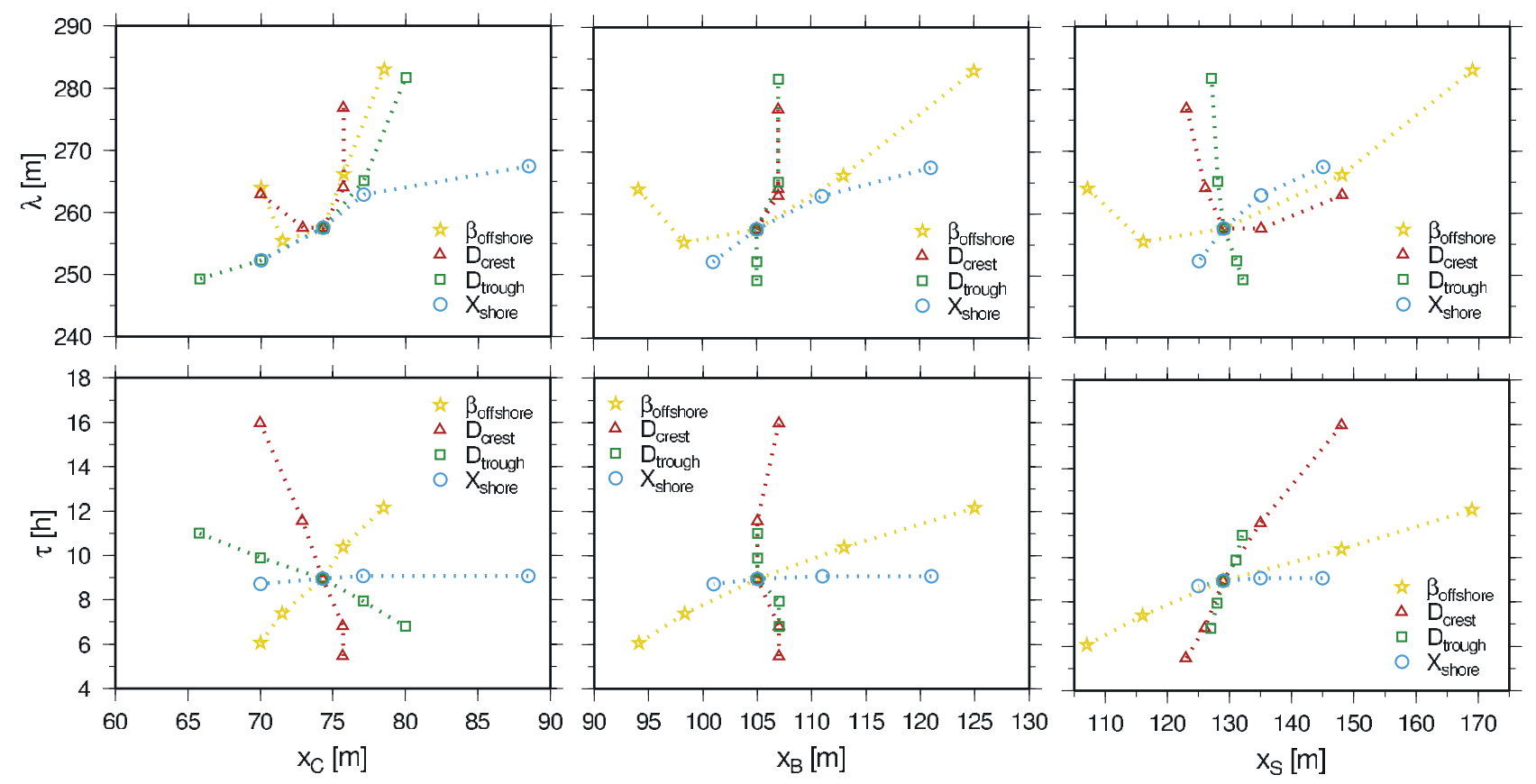

Figure 4. (top) Spacing $(\lambda)$ and (bottom) growth time $(\tau)$ of rip channels as a function of (left) the distance between shoreline and sandbar crest $X_{C}$; (middle) maximum breaking dissipation $X_{B}$; (right) surfzone $X_{S}$. Symbols indicate geometric variable of the cross-shore profile primarily changed.

wave breaking, and $X_{S}$, the distance between the shoreline and the location where wave dissipation due to wave breaking becomes significant (herein defined as the most offshore location where a value equal to $35 \%$ of the maximum dissipation across the whole profile is reached).

[10] Although all the experiments were performed under the same forcing conditions (wave height and period), there is no correlation between $\tau$ and $\lambda$ (Figure 3 ) indicating that the spatial and temporal scales related to rip channel growth are essentially uncoupled. An implication of this result is that, contrary to expectations, it is not necessarily true that it takes a longer time to develop rip channels of wider spacing. Also there is a significant spread in $\tau$ and $\lambda$ with values respectively ranging between $5 \mathrm{~h}$ and $16 \mathrm{~h}$, and $240 \mathrm{~m}$ and $290 \mathrm{~m}$. The largest variations in $\lambda$ are a function of $\beta_{\text {offshore }}$ and $D_{\text {trough }}$ (notice that for these runs, variations in $X_{\text {shore }}$ are relatively small). Largest variations in $\tau$ are associated with changes in $D_{\text {crest }}$. Overall, relative variations in $\tau$ are larger than in $\lambda$.

[11] We have tried to relate spacing and growth time of rip channels to parameters commonly used to characterize the surfzone width and that relate to either field or video observations. These indicators refer to the distance between shoreline and 1) sandbar crest, $\left.X_{C} ; 2\right)$ maximum breaking dissipation, $X_{B}$; and 3) surfzone width, $X_{S}$. To check the sensitivity of rip channel characteristics to profile shape, we have computed rip channel spacing and growth time for all profiles of Figure 2 and related them to the above indicators. As shown in Figure 4 variations in rip channel spacing and growth time can not be explained using $X_{B}$, a value usually derived from time-averaged video images [Lippmann and Holman, 1989]. $X_{C}$, a value that could be obtained surveying the surfzone or through video images (although with a certain degree of uncertainty related to wave characteristics), is a better descriptor for the variations in spacing.
A better predictor for the growth time of the features is provided by $X_{S}$. However, it is not clear if $X_{S}$ can be obtained through remote sensing techniques [Lippmann and Holman, 1989] or only through detailed measurements using densely spaced arrays of instruments.

[12] According to recent textbooks, the decisive factor in determining rip channel spacing remains wave height [Short, 1999; Woodroffe, 2003]. We have run a specific set of simulations increasing wave height while also varying the shape of the cross-shore profile. Figure 5 provides a good example, although with limited generality, on the

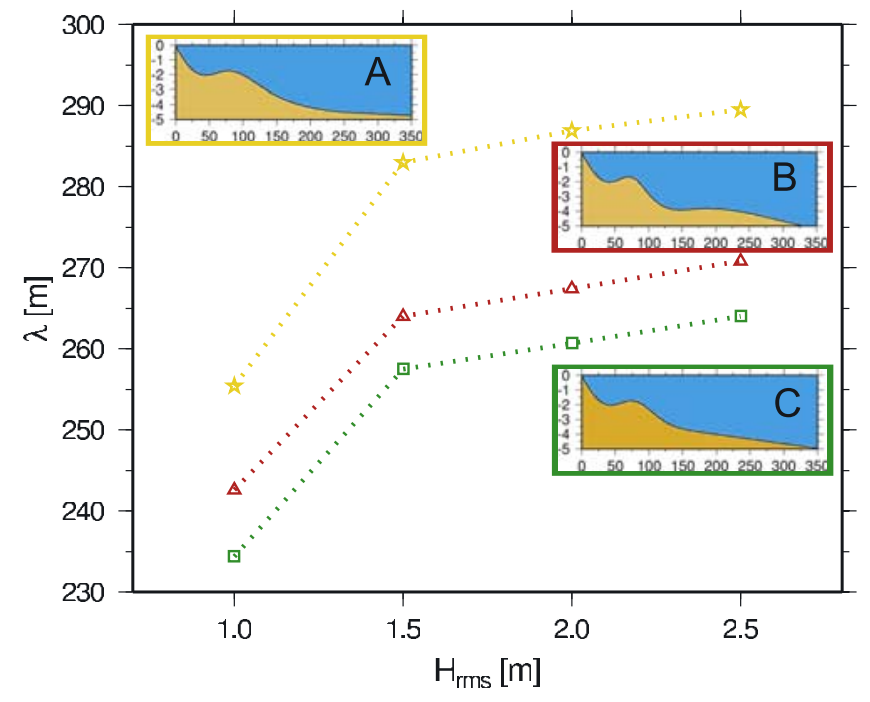

Figure 5. Variation in rip channel spacing $(\lambda)$ as a function of wave height and cross-shore profile configuration. Yellow, red, and green symbols respectively refer to simulations run using profile A, B, C. 
possible sources of scatter in field observations when the detailed cross-shore shape of the profile is not taken into account. In contrast to expectations, when the beach profile is also varied, rip channel spacing does not necessarily increase with increasing wave height. Figure 5 shows rip spacing as a function of wave height for three profiles that differ in the slope offshore of the sandbar ( $\beta_{\text {offshore }}$ experiments). The offshore slopes for profiles $\mathrm{A}, \mathrm{B}$ and $\mathrm{C}$ are $1.35^{\circ}, 2.98^{\circ}$ and $1.86^{\circ}$, respectively. One can see (Figure 5), that the rip spacing associated to a wave height of $1.5 \mathrm{~m}$ and profile $\mathrm{A}$ is larger than the spacing related to higher $H_{r m s}$ if the underlying initial bathymetry is described by profiles $\mathrm{B}$ or C. Similar trends are obtained when other profiles are used. For the same initial cross-shore profile, in agreement with previous findings, rip channel spacing increases with wave height (see trend of symbols of a specific color) but even small differences in the initial cross-shore profile can drive changes in $\lambda$ (compare profiles A and B in Figure 5) larger than the wavelength changes induced by changes in wave height. Overall, changes in the initial bathymetry and in the wave height for a specific profile result in similar wavelength variations (around 13\%).

\section{Discussion and Conclusions}

[13] Failure of previous attempts to correlate rip channel spacing to wave characteristics [Huntley and Short, 1992; Short and Brander, 1999] or indicators of surfzone width [Whyte et al., 2005; Holman et al., 2006] has been ascribed to either uncertainties in the detailed estimation of hydrodynamic descriptors or an indication that no relationship actually exists. Our results indicate that the nearshore is a more complicated system than previously envisaged and the shortcoming is not necessarily related to the field measurements but rather to the understanding of the system dynamics. The spacing of rip channels does not appear to be only a response to hydrodynamic forcing (wave height and period) but a more complex (and still undetermined) function strongly influenced by the pre-existing morphology. Our simulations confirm the link between wave height and rip channel spacing (which in some situations might become the dominant source of spacing variability) but also point at the so far neglected role of the pre-existing bathymetry (sensitivity to initial conditions appears to be as important as external hydrodynamic forcing).

[14] Given the practical limitations (time, cost and seastate) in obtaining systematic and detailed surfzone bathymetry, predictability of rip channel spacing (or even trends in predictability) is limited and the scatter in the observed wavelengths of at least 13\% (resulting for example from errors in the estimation of the bathymetry) should not be unexpected. As a result of the large range of characteristic growth times under the same hydrodynamic conditions (from $\simeq 6$ to $\simeq 16$ hours), even the "if" and "when" of rip channel occurrence becomes unpredictable. For example, rip channels with a characteristic growth time around 12 hours might never develop at locations where tidal range is large (tides change water depths, and so all the characteristics of the cross-shore sandbar profile, at the same rate as the temporal scale of pattern development). Also, steady forcing conditions would be required for extended time (note that 12 hours refers only to the initial development of the features). On the other hand onshore/offshore sandbar migration might affect the cross-shore profile in such a way that rip channel development subsequently occurs. The frequently reported limitations in spacing regularity [Van Enckevort et al., 2004; Holman et al., 2006] can also be qualitatively explained by these results as even small alongshore non-uniformities in the bathymetry (e.g., depth of the sandbar trough, slope offshore of the sandbar) can drive the growth of rip channel systems characterized by different alongshore length scales whose interaction might lead to the frequently observed nonlinear phenomena (e.g., merging/splitting [Van Enckevort et al., 2004]) and in turn to a lack of pattern regularity. Alongshore variability of crossshore profiles is a common characteristic of barred beaches [Larson and Kraus, 1994; Hsu et al., 2006] and is often larger than the one considered in this study (Figure 2). The implications of these results are relevant: i) it is likely that many other geomorphic patterns developing in nonlinear, dissipative environments [Werner, 2003] display similar sensitivity to pre-existing morphology; ii) the search for a rip channel predictor will need to fully account for the shape of the underlying bathymetry. Given the difficulties in its detailed estimation it appears likely that a predictor through the analysis of numerical models will be difficult to apply in the field. The new challenge becomes quantifying the effect of variability in the hydrodynamic forcing and in the shape of the cross-shore profile in order to possibly define inherent limits in predictability of rip channel characteristics.

[15] Acknowledgments. DC and AF acknowledge funding from the Ministerio de Ciencia y Tecnologia of Spain (PUDEM project, contract REN2003-06637-C02-01/MAR) and the 'Ramón y Cajal' contract of DC. $\mathrm{GC}$ acknowledges funding from the (New Zealand) Foundation for Research, Science, and Technology (contract C01X0401). ND gratefully acknowledges the financial support of EPSRC through the grant GR/ S19172/0. Thanks to K. McLeod for assistance in preparing Figure 5.

\section{References}

Bohem, A. B. (2003), Model of microbial transport and inactivation in the surf zone and application to field measurements of total coliform in Northern Orange County, California, Environ. Sci. Technol., 36, 5511-5517.

Calvete, D., N. Dodd, A. Falqués, and S. M. van Leeuwen (2005), Morphological development of rip channel systems: Normal and nearnormal wave incidence, J. Geophys. Res., 110, C10006, doi:10.1029/ 2004JC002803.

Church, J. C., and E. B. Thornton (1993), Effects of breaking wave induced turbulence within a longshore current model, Coastal Eng., 20, 1-28.

Damgaard, J., N. Dodd, L. Hall, and T. Chesher (2002), Morphodynamic modeling of rip channel growth, Coastal Eng., 43, 199-221.

Falqués, A., G. Coco, and D. A. Huntley (2000), A mechanism for the generation of wave-driven rhythmic patterns in the surf zone, J. Geophys. Res., 105, 24,071-24,088.

Garnier, R., D. Calvete, A. Falqués, and M. Caballeria (2006), Generation and nonlinear evolution of shore-oblique/transverse sand bars, J. Fluid Mech., 567, 327-360.

Holman, R. A., G. Symonds, E. B. Thornton, and R. Ranasinghe (2006), Rip spacing and persistence on an embayed beach, J. Geophys. Res., 111, C01006, doi:10.1029/2005JC002965.

Hsu, T. W., L. F. Tseng, and C. P. Lee (2006), A new shape function for bartype beach profiles, J. Coastal Res., 22(3), 728-736.

Huntley, D. A., and A. D. Short (1992), On the spacing between observed rip currents, Coastal Eng., 17, 211-225.

Larson, M., and N. C. Kraus (1994), Temporal and spatial scales of beach profile change, Duck, North Carolina, Mar. Geol., 117, 75-94.

Lippmann, T. C., and R. A. Holman (1989), Quantification of sand bar morphology: A video technique based on wave dissipation, J. Geophys. Res., 94, 995-1011.

Long, J. W., and H. T. Özkan-Haller (2005), Offshore controls on nearshore rip currents, J. Geophys. Res., 110, C12007, doi:10.1029/2005JC003018.

MacMahan, J. H., E. B. Thornton, and A. J. H. M. Reniers (2006), Rip current review, Coastal Eng., 53, 191-208. 
Reniers, A. J. H. M., J. A. Roelvink, and E. Thornton (2004), Morphodynamic modeling of an embayed beach under wave group forcing, J. Geophys. Res., 109, C01030, doi:10.1029/2002JC001586.

Short, A. D. (1999), Handbook of Beach and Shoreface Morphodynamics, John Wiley, Hoboken, N. J.

Short, A. D., and R. W. Brander (1999), Regional variations in rip density, J. Coastal Res., 15(3), 813-822.

Short, A. D., and C. L. Hogan (1995), Rip currents and beach hazards: Their impact on public safety and implications for coastal zone management, J. Coastal Res., SI 12, 197-209.

Soulsby, R. L. (1997), Dynamics of Marine Sands, Thomas Telford, London

Talbot, M. M., and G. C. Bate (1993), Rip current characteristics and their role in the exchange of water and surf diatoms between the surf zone and nearshore, Estuarine Coastal Shelf Sci., 25(6), 707-720.

van Enckevort, I. M. J., B. G. Ruessink, G. Coco, K. Suzuki, I. L. Turner, N. G. Plant, and R. A. Holman (2004), Video observations of nearshore crescentic sandbars, J. Geophys. Res., 109, C06028, doi:10.1029/2003JC002214.

Werner, B. (2003), Modeling landforms as self-organized, hierarchical dynamical systems, in Prediction in Geomorphology, Geophys. Monogr.
Ser., vol. 135, edited by R. M. Iverson and P. R. Wilcock, pp. 133-150, AGU, Washington, D. C.

Whyte, D., I. L. Turner, and R. Ranasinghe (2005), Rip characterisation on the Gold Coast, Australia: An analysis using coastal imaging techniques, paper presented at 17th Australasian Coastal and Ocean Engineering Conference, Inst. of Eng., Adelaide, S. Aust., Aust., 20-23 Sept.

Woodroffe, C. D. (2003), Coasts: Form, Process, and Evolution, Cambridge Univ. Press, New York.

D. Calvete and A. Falqués, Dept. de Física Aplicada, Universitat Politécnica de Catalunya, Campus Nord Modùl B4, E-08034 Barcelona, Spain. (calvete@fa.upc.edu; falques@fa.upc.edu)

G. Coco, National Institute of Water and Atmospheric Research, P.O. Box 11-115, Hamilton, New Zealand. (g.coco@niwa.co.nz)

N. Dodd, School of Civil Engineering, University of Nottingham, University Park, Nottingham NG7 2RD, UK. (nick.dodd@nottingham. ac.uk) 